\title{
EVALUATION OF THE PATIENT SAFETY CULTURE IN NEONATAL INTENSIVE CARE ${ }^{1}$
}

\author{
Andréia Tomazoni², Patrícia Kuerten Rocha³, Denise Miyuki Kusahara ${ }^{4}$, Ana Izabel Jatobá de Souza ${ }^{5}$ Taise \\ Rocha Macedo ${ }^{6}$
}

${ }^{1}$ Partial results of the dissertation - Patient Safety Culture in Neonatal Intensive Care Units, presented to the Nursing Graduate Program of the Universidade Federal de Santa Catarina (UFSC), 2013.

${ }^{2}$ M.Sc in Nursing. UFSC. Florianópolis, Santa Catarina. Brazil. E-mail: andreiatomazoni@gmail.com

${ }^{3}$ Ph.D. in Nursing. Professor of the Nursing Department of UFSC. Florianópolis, Santa Catarina. Brazil. E-mail: pkrochaucip@ gmail.com

${ }^{4}$ Ph.D. in Sciences. Nurse of the Pediatric Nursing Department of the Paulista School of Nursing of UNIFESP. São Paulo, São Paulo, Brazil. E-mail: dkusahara@unifesp.br

${ }^{5}$ Ph.D. in Nursing. Professor of the Nursing Department of UFSC. Florianópolis, Santa Catarina. Brazil. E-mail: aijsenf@gmail.com

${ }^{6}$ Master's student of the Nursing Graduate Program of UFSC. Florianópolis, Santa Catarina. Brazil. E-mail: taiserm@hotmail.com

ABSTRACT: This quantitative, survey type study aimed to analyze the patient safety culture of the nursing and medical teams of public hospitals of Florianopolis. A total of 141 professionals participated, with data collected between February/April 2013, after approval by the Ethics Committee. The Hospital Survey on Patient Safety Culture was used and the 12 dimensions of the culture were evaluated. Descriptive analysis was performed, classifying the dimensions into areas of strength or critical areas. Despite not verifying a specific area of strength, the dimensions with the best evaluation were Supervisor/manager expectations and actions promoting safety and Organizational learning - continuous improvement. The dimensions with the highest percentage of negative responses, identified as critical were: Non-punitive response to errors and Management support for safety. The safety culture in the Neonatal Intensive Care Units presented aspects that could potentially become areas of strength. Cultural changes are necessary, especially in addressing errors. DESCRIPTORS: Patient safety. Organizational culture. Neonatal nursing. Neonatal Intensive Care Units.

\section{AVALIAÇÃO DA CULTURA DE SEGURANÇA DO PACIENTE EM TERAPIA INTENSIVA NEONATAL}

RESUMO: Estudo quantitativo, tipo survey, cujo objetivo foi analisar a cultura de segurança do paciente na perspectiva das equipes de enfermagem e médica de hospitais públicos de Florianópolis. Participaram 141 profissionais, com dados coletados entre fevereiro/abril de 2013, com o instrumento Hospital Survey on Patient Safety Culture, avaliando 12 dimensões da cultura de segurança, após aprovação pelo Comitê de Ética. Realizou-se análise descritiva, classificando as dimensões em áreas de força ou críticas. Apesar de não ocorrer uma área de força específica, destacaram-se como áreas melhor avaliadas as expectativas e ações do supervisor/chefia para promoção da segurança do paciente e o aprendizado organizacional - melhoria contínua. Como área crítica, identificou-se: Resposta não punitiva ao erro e Apoio da gestão hospitalar para segurança do paciente. A cultura de segurança nas Unidades de Terapia Intensiva Neonatal apresenta áreas potenciais para se tornarem fortes. Conclui-se que são necessárias mudanças culturais, principalmente na abordagem dos erros. DESCRITORES: Segurança do paciente. Cultura organizacional. Enfermagem neonatal. Unidades de Terapia Intensiva Neonatal.

\section{EVALUACIÓN DE LA CULTURA DE LA SEGURIDAD DEL PACIENTE EN CUIDADOS INTENSIVOS NEONATAL}

RESUMEN: Estudio cuantitativo, tipo survey, con la finalidad de analizar la cultura de seguridad del paciente del personal de enfermería y médico de cuatro hospitales públicos. Fueron añadidos 141 profesionales. Los datos recolectados entre febrero/abril de 2013, con la aplicación del Hospital Survey on Patient Safety Culture. Fue utilizada estadística descriptiva, clasificando las dimensiones por áreas de fortaleza o crítica. A pesar de no ocurrir un área de fuerza particular, se destacaron como las mejores áreas las Expectativas y acciones del supervisor/jefe para la promoción de la seguridad, y, Aprendizaje organizacional - mejora continua. Como área crítica se identificaron: Respuesta no punitiva al error y Apoyo a la gestión hospitalaria para la seguridad. La cultura de seguridad en las Unidades de Cuidados Intensivos Neonatales tiene potencial para convertirse en área fuerte. Llegamos a la conclusión de que se necesitan cambios culturales, especialmente en el tratamiento de errores.

DESCRIPTORES: Seguridad del paciente. Cultura organizacional. Enfermería neonatal. Unidades de Cuidado Intensivo Neonatal. 


\section{INTRODUCTION}

Discussions regarding patient safety during hospitalization increased after the publication of the American report To err is human: building a safer health care system in 2000, which indicated that, worldwide, millions of people suffer injuries and death resulting from health practices. ${ }^{1}$

Referring to patient safety in the Neonatal Intensive Care Unit (NICU) environment and combining this with the characteristics of newborns, the safety risks may be higher in this context. A study in a NICU of a Brazilian philanthropic hospital showed that, of the 218 neonates admitted over a five-month period, 183 (84\%) experienced adverse events. The majority of these patients suffered more than one adverse event, with a mean rate of 2.6 adverse events per patient, over a mean hospitalization period of 13.5 days. $^{2}$

Given the statistics related to harm caused to patients, in 2004 the World Health Organization (WHO), concerned with the issue of patient safety, launched the World Alliance for Patient Safety, aiming to combat problems related to this issue. ${ }^{3}$

In this context, various partnerships have been entered into seeking solutions to improve patient safety. Among the strategies disclosed by agencies, such as the National Patient Safety Agency (NPSA), the Agency for Healthcare Research and Quality (AHRQ) and the National Quality Forum (NQF), is the incorporation of the safety culture into healthcare institutions. ${ }^{4-5}$

In the Brazilian context, the creation of the National Patient Safety Program (PNSP) by the Ministry of Health (MS) and the National Health Surveillance Agency (ANVISA) was important to improve safety and reduce the incidence of adverse events. It should be noted that one of the strategies of this program is to promote the safety culture. $^{6}$

Safety culture is defined as the behavioral patterns of individuals and groups, which may be based on their values and attitudes, and that determine the way they will perform their work. Organizations that present a positive safety culture are characterized by good communication, by sharing the perception of the importance of safety and by confidence in the preventive measures adopted. ${ }^{7}$

The Brazilian Association of Intensive Care Medicine (AMIB) recommends, in the Safe Intensive Care Units Guide (GUTIS), the development of a patient safety culture. In this, they state that the safety culture determines the personality profile of the Intensive Care Unit (ICU), i.e., the way the actions are carried out, which is determined by the way of working in groups. Thus, the following aspects are considered characteristics of a safe ICU: strong leadership, open communication, team spirit, rapid and effective responses to the challenges, culture of risk prevention, and error reporting based on a non-punitive culture. ${ }^{8}$

In order to understand the causes of errors, decrease the occurrence of adverse events in the NICU and promote quality care and safety, it is essential to comprehend the cultural dimensions from the perspective of the healthcare professionals. The aim of this study was to analyze the patient safety culture from the perspective of nursing and medical teams of NICUs in public hospitals.

\section{METHODOLOGY}

This descriptive, quantitative, cross-sectional, survey type study was conducted in four type II NICUs of four public hospitals in the Greater Florianópolis region of Santa Catarina, Brazil.

The population consisted of 181 professionals from the nursing and medical teams of the NICUs. The sample was intentional, non-probabilistic, and considered the following inclusion criteria: to be a nurse, nursing technician, auxiliary nurse or physician, to have been working in the NICU for over two months, and to return the completed data collection instrument. The exclusion criteria were: professionals that were not from the nursing or medical teams, professional of the teams that were not in the sector due to vacation, sick leave, maternity leave and/or sabbatical, and the completion of less than half of the instrument. Following these criteria, the sample totaled 141 professionals.

Data collection took place between February and April 2013 through the application of the Hospital Survey on Patient Safety Culture (HSOPSC) instrument. After authorization from the authors for translation and application of the instrument in this study, the translation followed the steps proposed in the Translation Guidelines for the AHRQ Surveys on Patient Safety Culture. ${ }^{9}$ The HSOPSC allows evaluation of the patient safety culture from the perspective of the professionals, through 42 items, grouped into 12 dimensions, with each dimension containing three or four items. Addition- 
ally, it allows the subjects to rate the patient safety of their institution and also quantify the number of events reported. Each item provides five response options, through a Likert scale. ${ }^{10}$

For the initiation of the data collection, the research project was presented by the researchers of this study to the teams of each unit. The Informed Consent form was delivered and each subject received an envelope containing the HSOPSC instrument translated into Portuguese, which was completed and sealed by the responding professional, anonymously, and then deposited in a box. Instruments in which more than half the items were answered were registered in the database. ${ }^{10}$ It should be noted that not all the items of the 12 dimensions were answered, therefore there is a difference in the total number of responses for each dimension.

Descriptive analysis was used and the guidelines of the AHRQ were followed, grouping the responses obtained into three categories: a) positive responses: strongly agree, agree, always and most of the time; negative responses: strongly disagree, disagree, never and rarely; c) neutral responses: $b$ ) neither agree nor disagree and sometimes. The score of each dimension was calculated through the percentage of positive, negative and neutral responses for the items of each dimension. Thus, the dimensions were classified into areas of strength, considered when $75 \%$ of the subjects respond strongly agree/agree or most of the time/ always to the positively formulated questions and strongly disagree/disagree or never/rarely to the negatively formulated questions. The critical areas are classified when $50 \%$ or more of the subjects respond negatively, opting for strongly disagree/disagree or never/rarely for the positively formulated questions, or using strongly agree/ agree, always/most of the time for the negatively formulated questions. ${ }^{11}$

Ethical issues followed Resolution 466/2012 of the National Health Council of the Ministry of Health. The research project was submitted to Plataforma Brasil and obtained approval from the Ethics Committee, CAAE n . 05274612.7.0000.0121.

\section{RESULTS}

The data revealed that $58(41 \%)$ professionals were nursing technicians, 48 (34\%) physicians,
$23(16 \%)$ nurses and $12(9 \%)$ auxiliary nurses. Of these, $76(54 \%)$ professionals had worked in the NICU for less than ten years. The majority of them, 93 (66\%), had worked for more than 10 years in the profession and 97 (69\%) worked less than 40 hours per week. All the professionals who completed the instrument performed direct patient care. Considering the 42 items of the instrument a total of 2546 (43\%) positive responses, 1917 $(32 \%)$ and negative responses and 1378 (23\%) neutral responses were obtained. Of the grouped items of the 12 dimensions, the mean percentage of positive, negative, neutral responses for each was obtained (Figure 1).

Following the guidelines of the authors of the data collection instrument, the results did not show any dimension with positive response scores above $75 \%$ to be classified as an area of strength, however, the dimensions with the highest percentage of positive responses and the items of these dimensions that received better evaluations can be highlighted. Thus, the dimension 'Supervisor/manager expectations and actions promoting safety', which is characterized by the attitudes of the supervisor/manager related to safety promotion is prominent. The total positive responses, 347 $(61 \%)$, was the highest in all the dimensions. The dimension consists of four items, with the item that received the best evaluation being "Whenever pressure builds up, my supervisor/manager wants us to work faster, even if it means taking shortcuts", where $106(75 \%)$ professionals rejected that assertion, indicating a positive point of the safety culture.

The second dimension highlighted was "Organizational learning - continuous improvement", which concerns the culture of learning, in which errors are studied, leading to positive changes. ${ }^{10}$ This dimension obtained $252(59 \%)$ positive responses and, among the three items that compose it, the most prominent was "We are actively doing things to improve patient safety", with 95 (67\%) subjects agreeing with this statement.

In the third dimension highlighted, "Teamwork within the unit" which addresses support, respect among the professionals and teamwork, there were $318(57 \%)$ positive responses, with 111 $(80 \%)$ of the professionals agreeing that "When a lot of work needs to be done quickly, we work together as a team to get the work done". 


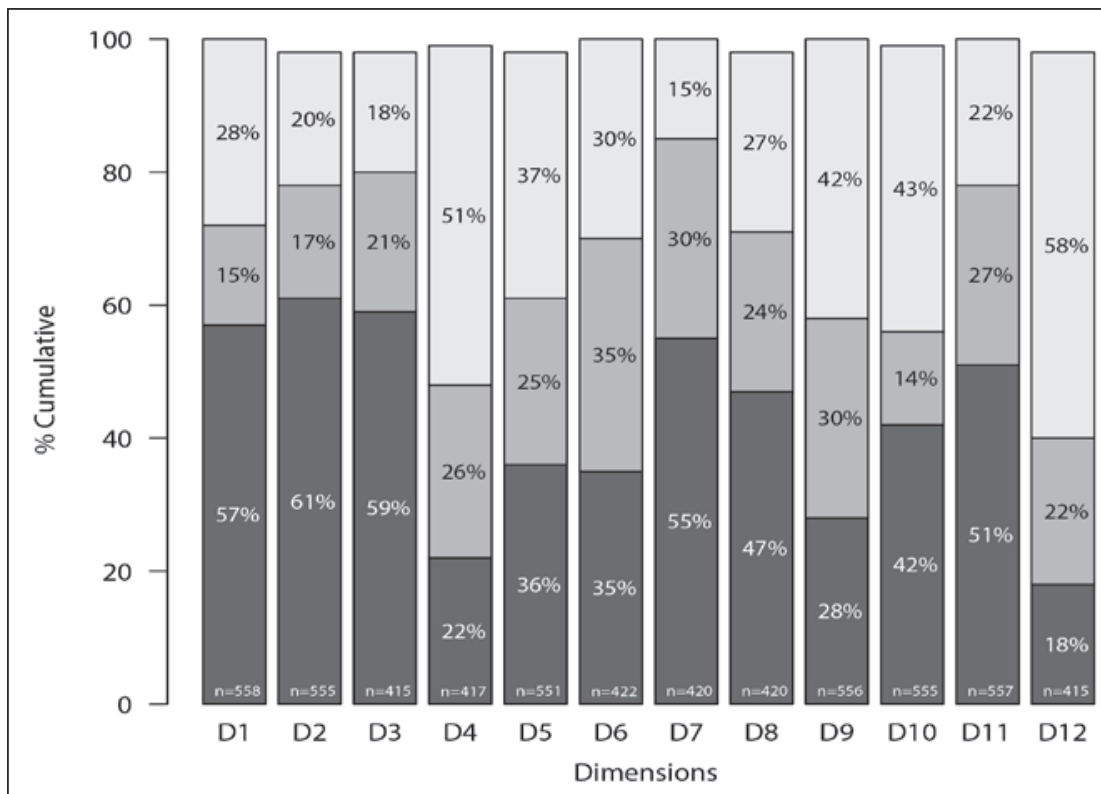

D1: Teamwork within the unit;

D2: Supervisor/manager expectations and actions promoting safety;

D3: Organizational learning - continuous improvement;

D4: Management support for patient safety;

D5: Overall perceptions of patient safety;

D6: Feed-back and communication about error;

D7: Communication openness;

D8: Adverse event reporting and recording;

D9: Teamwork between units;

D10: Staffing;

D11: Hand-offs and trasitions;

Responses

D12: Non-punitive response to error

Figure 1 - Number of responses for each dimension and percentage of positive, neutral and negative responses for the twelve dimensions of patient safety culture according to the HSOPSC, in Neonatal Intensive Care Units of Public Hospitals in the Greater Florianópolis region, Santa Catarina, Brazil, 2013

Regarding the fourth dimension, "Communication openness", which is characterized by the freedom of professionals to report situations that may affect the patient, 233 (55\%) positive responses were obtained, highlighting the item "Staff will freely speak up if they see something that may negatively affect patient care", where 103 $(73 \%)$ professionals agreed with this issue.

Conversely, some dimensions presented high percentages of negative responses. Those that obtained $50 \%$ or more were classified as critical patient safety culture areas. The first critical area was "Non-punitive response to error", which obtained 245 (58\%) negative responses. Composed of three items, those that represent the major problems faced were "When an event is reported, it feels like the person is being written up, not the problem", with agreement by 64 (90\%) of the professionals, and "Staff feel like their mistakes are held against them", in which 85 (60\%) agreed with this statement.

The second dimension classified as a critical area was "Management support for patient safety", which considers that the hospital provides a favorable working environment for the promotion of patient safety. This dimension obtained $216(51 \%)$ negative responses. The majority of the professionals, 73 (52\%) disagreed with the item "Hospital management provides a work climate that promotes patient safety", and 73 (52\%) of them agreed that "Hospital management seems interested in patient safety only after an adverse event happens".

The dimension "Staffing" assumes that there are enough employees to cope with the workload. This dimension was assigned 244 (43\%) negative 
responses, in which 100 (71\%) professionals disagreed with "We have enough staff to handle the workload". The dimension "Teamwork between the hospital units" received 234 (42\%) negative responses. Of this total, $86(61 \%)$ professionals agreed that "Hospital units do not coordinate well with each other".

In addition to evaluating the safety culture dimensions, the instrument presents two outcome variables of the patient safety culture. One of these is the perception of the professionals regarding patient safety, rating the safety in their unit, and the other deals with the number of events that the professional reported to his supervisor/manager in the previous 12 months. In this way, the professionals chose, according to their perceptions, from five available options to rate the patient safety of their unit. The results revealed that safety was predominantly considered to be "Acceptable", with $64(45 \%)$ of the professionals opting for this classification, and another 54 (38\%) considering safety to be "Very good" (Figure 2.A).

Regarding the second outcome variable, which deals with the reporting of events, the results indicated that among the options, ranging from 'no event reported' to '21 events reported or more', 120 (85\%) professionals had reported less than five events in the previous 12 months. The majority of this total of 120 professionals, said that they reported on average one to two events, represented by 45 (32\%) professionals. Another 46 (33\%) reported no event (Figure 2.B).

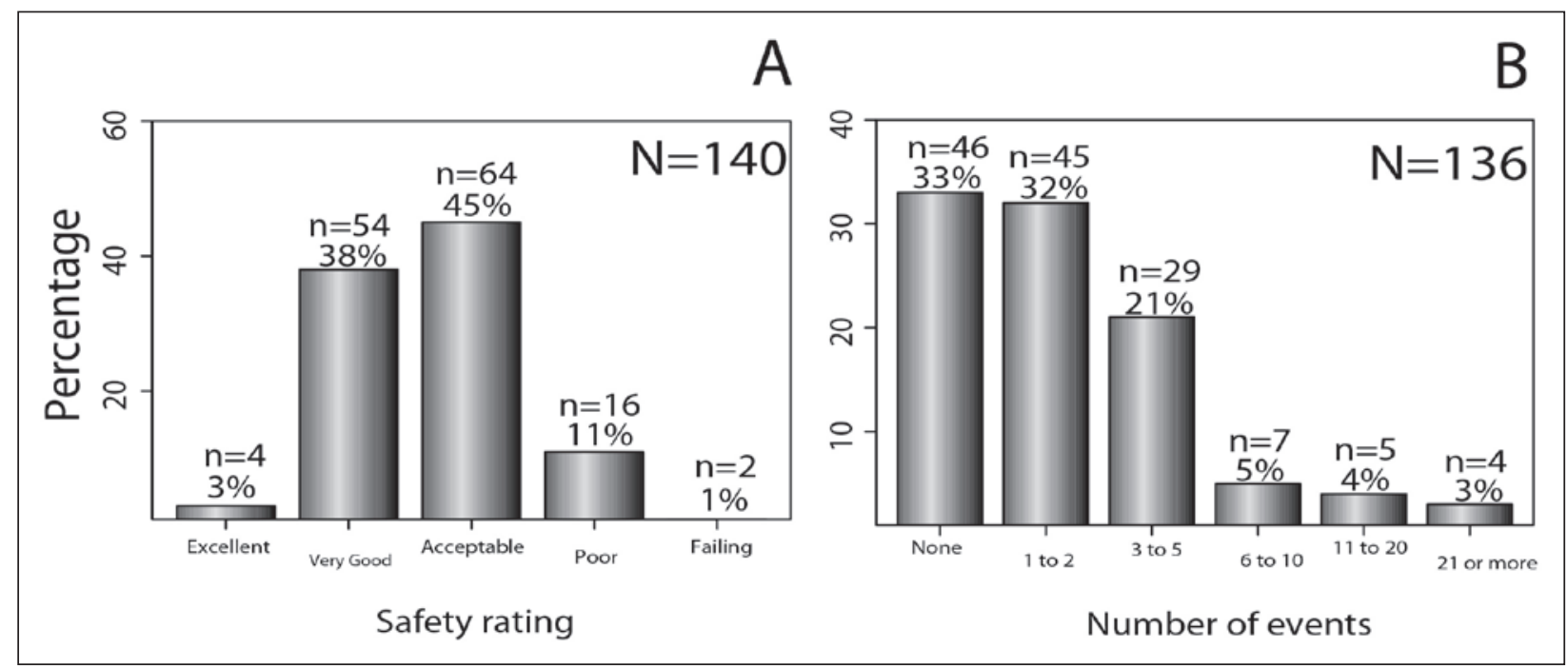

Figure 2 - (A) Mean percentage of responses regarding the patient safety rating and (B) Mean percentage of responses regarding the number of events reported to the supervisor/manager in the previous twelve months in Neonatal Intensive Care Units of public hospitals in the Greater Florianópolis region, Santa Catarina, Brazil, 2013

\section{DISCUSSION}

Regarding the areas of strength, no dimension was classified as such. However, it is considered that the dimensions "Supervisor/manager expectations and actions promoting safety" (61\%) and "Organizational learning - continuous improvement" (59\%) these being the main ones, demonstrate advances in the safety culture and have the potential to become areas of strength in the NICUs. A study conducted in two adult ICUs in Brazilian public hospitals, with 86 nurses and using the same study instrument, also presented as outstanding results the dimensions "Supervisor/manager expectations and actions promoting safety" and "Organizational learning - continuous improvement", with $49 \%$ and $46 \%$ of positive responses, respectively. ${ }^{12}$ However, this differed from the results found in the present study, in which the dimension with the most positive assessment was "Teamwork within the unit", with $63 \%$ of positive responses. ${ }^{12}$

Furthermore, it is emphasized that the results of the present study regarding the two dimensions with a potential for being areas of strength are similar to a survey conducted in eight hospitals in Spain, with 1,113 healthcare professionals, in which $63 \%$ of the responses were positive for "Supervisor/manager ex- 
pectations and actions promoting safety" and $53 \%$ for "Organizational learning - continuous improvement" ${ }^{13}$ This is also in agreement with a study conducted in 11 Palestinian hospitals, with 1,408 professionals, which also obtained positive responses of $62 \%$ and $56 \%$, respectively, for these dimensions. ${ }^{14}$ These dimensions were also evaluated in 1,128 public hospitals of the United States by 567,703 healthcare professionals, in which $75 \%$ of the responses were positive for "Supervisor/manager expectations and actions promoting safety" and $72 \%$ for "Organizational learning - continuous improvement". ${ }^{12}$ Also, in a study conducted in 32 hospitals in China, with 1,160 professionals, these dimensions obtained $63 \%$ and $88 \%$, respectively. ${ }^{15}$

These results highlight that although there are cultural particularities among these countries, the percentage of positive responses indicates that the actions of the supervisor/manager and organizational learning are positive factors of the patient safety culture, with the scores obtained in the different studies being similar. It was noted that there was a concern among the professionals of the four NICUs, particularly on behalf of the supervisors/managers, to improve safety by encouraging the workers to adhere to safety standards and also to learn from the errors that are reported and make changes.

The literature indicates leadership and learning as subcultures of the safety culture, and that leadership is a key element for the creation and promotion of organizational learning - which seeks to comprehend the causal factors of errors - extracting educational lessons to improve the system. Thus, organizational learning and leadership as subcultures, show that the former is only effective if leaders show interest in learning and improving the care processes from experiences. When the leadership promotes a culture of learning, safety awareness is created among the workers and a learning environment is promoted. ${ }^{16}$

Conversely, the areas classified as critical indicated that a safety culture persists in the NICUs that disregards the health area as being of high risk and approaches errors as individual causes, highlighting the dimension "Non-punitive response to error" (58\%) and "management support for patient safety" (51\%). In the opinion of the professionals, the dimension "Non-punitive response to error" mainly indicates fragility with regard to the reporting of errors, as the employees feel attention directed more toward the person that committed the error, rather than trying to understand the factors that caused the error.

In this dimension, similar results were obtained to a study performed in two Brazilian adult ICUs, ${ }^{14}$ and a study conducted in Palestine, ${ }^{12}$ cited above, both of which obtained $17 \%$ of positive responses. However, it was noted that in the United States this percentage increased to $44 \%{ }^{11}$ and to $60 \%$ in China, ${ }^{15}$ indicating that these countries are ahead in the development of their patient safety cultures.

In Brazil it is evident from the results obtained, that a culture of blame of the subjects who commit errors persists, where mistakes are seen as the consequence of personal factors resulting from inattention or lack of competence. However, the psychologist James Reason, in his theory on error, claims that it is part of human nature to commit errors, and that these happen through a set of existing sequential failures in the health system, and not merely due to an isolated factor, such as the carelessness of the professional. ${ }^{17}$

The predominant culture with a person centered approach, rather than a system centered approach to errors, interferes with the identification of the failures, preventing changes in the search for improvements from being made. A study performed with 70 nurses working in the intensive care area in Brazil, inquired about the occurrence of punishment when errors were reported, with 52 (74\%) of the professionals choosing the answer that punishments "sometimes" and "always" occurs. Among the 100 types of punishments mentioned, $49(49 \%)$ were through verbal warnings and $33(33 \%)$ written warnings, $11(11 \%)$ suspension, 5 (5\%) dismissal, and $2(2 \%)$ psychological harassment. ${ }^{18}$

The second critical area highlighted was "Management support for patient safety", and, in the opinion of the study subjects, there was little commitment and support from the management with respect to patient safety. It should be noted that in the United States a report showed that management support was considered a potential area of strength with $72 \%$ of positive responses, ${ }^{11}$ while the results of the present study showed $22 \%$ of positive responses. Thus, to establish a patient safety culture, there must be commitment of the managers of institutions, with them involving themselves in the work context in order to identify the difficulties, therefore enabling the communication between the different hierarchical levels to be strengthened. ${ }^{19}$ 
Furthermore, in this study, the judgment of the subjects was highlighted regarding the high workload due to the condition of insufficient staff, indicating risks to patient safety. A study analyzed the nature of medication errors in a NICU and a Pediatric Intensive Care Unit (PICU) of a hospital in Israel, in which the results indicated the workload, a system factor, to be the main cause of adverse events. ${ }^{20}$

Despite the critical areas evidenced, the majority of the subjects rated patient safety as "Acceptable" or "Very good" in the NICUs. A study that aimed to examine the safety culture, performed with 3,779 professionals from hospitals in the Netherlands, 196.462 from the USA and 10,146 from Taiwan, showed that the majority of the subjects of the North American hospitals - considered the safety to be "Excellent" (25\%) or "Very good" (48\%). The professionals from the Netherlands and Taiwan, mostly considered safety to be "Acceptable", with $63 \%$ and $51 \%$ of the subjects of these countries, respectively, opting for this statement. ${ }^{21}$

Regarding the reporting of events, the results showed that the majority of the subjects reported an average of one to two events per year, with this low adherence to reporting possibly being related to various factors, including the punitive culture. Underreporting of errors and adverse events takes place due to the fear of suffering professional consequences, masking the reality of the statistics. As observed in a study performed with nurses of the Brazilian intensive care area, 115 reasons were mentioned for the occurrence of underreporting, with $29(25 \%)$ being due to work overload, 26 (23\%) forgetting, 23 (20\%) not valorizing adverse events, 18 (16\%) feelings of fear, and $13(11 \%)$ due to embarrassment. ${ }^{18}$

Thus, the underreporting of errors prevents their analysis and consequently the determination of the causes of origin, which could indicate the failures in the system that are leading to the occurrence of these situations. When errors are reported it is possible to plan actions to prevent them from happening again, through the detection of the organizational and cultural factors, problems in the provision of care and system defense barriers. ${ }^{22}$

A literature review showed that institutions that use voluntary reporting of errors tend to have a higher rate of reports than those using obligatory notification. Thus, by implementing voluntary error reporting, based on a non-punitive culture, it is possible to obtain information on the type, etiology, development and the prevention of errors in the NICU. ${ }^{23}$

Concern regarding all these issues surrounding patient safety has lead to strategies being adopted at the international (including strategies unilaterally promoted by different countries) and national level, such as the World Alliance for Patient Safety promoted by the WHO and the creation of the National Patient Safety Program (PNSP) by the MS and ANVISA in Brazil, as well as strategies that incorporate the culture of safety into health institutions promoted by the NPSA, AHRQ and NQF. . $^{4-6}$

The aspects that characterize a safe ICU, such as: strong leadership, open communication, teamwork, rapid and effective reaction to the challenges, and a culture of risk prevention and error reporting based on a non-punitive culture, ${ }^{8}$ can be seen as incongruent by the different professionals and, therefore, have an influence on their perceptions regarding patient safety. The literature assumes that different perceptions of patient safety exist among healthcare professionals, even within the same professional category ${ }^{24-25}$, and that the perceptions are connected and have important influences on the working conditions of the professionals ${ }^{26}$ and, therefore, need to be considered.

\section{FINAL CONSIDERATIONS}

The results show that, in the NICUs, patient safety is a sensitive issue, indicating that cultural factors need to be rethought. Although presented with advances and studies in this area that indicate the main factors that affect safety, there is still a culture in these environments in which errors are judged as incompetence. Organizational issues, such as inadequate numbers of professionals in relation to the amount of work, were also evidenced, being a point of great impact on safety, as shown in the literature. Also, according to the nursing and medical professionals, the hospital management did not prioritize patient safety and did not provide a working environment that motivates its promotion.

However, the positive factors of the patient safety culture were evidenced by the intention of the supervisors and managers of these units to prioritize safety and also by the characteristics that indicated efforts to learn and find solutions when errors are reported. Accordingly, we emphasize that to develop a patient safety culture in the NICUs, these positive factors should be 
improved, while the critical factors should be reviewed, especially replacing the person approach to errors for the system approach, attempting to detect failures in the system and correct them. Therefore, it is fundamental to sensitize hospital managers so that they understand that patient safety is compromised by failures in the system and that safety should be a priority, so that it is possible to create a climate of safety.

It is also fundamental to develop scientific studies that address in detail each of the dimensions mentioned in this study, so that it is possible to develop actions that enable professionals and managers to rethink values to ensure patient safety during hospitalization.

\section{REFERENCES}

1. Konh LT, Corrigan JM, Donaldson MS. Errors in health care: a leading cause of death and injury. In: Konh LT, Corrigan JM, Donaldson MS. To err is human: building a safer health care system. Washington (DC): Institute of Medicine; 2000; 26-48.

2. Ventura, CMU, Alves JGB, Meneses J. Eventos adversos em Unidade de Terapia Intensiva Neonatal. Rev Bras Enferm. 2012 Jan-Fev; 65(1):49-55.

3. Donaldson L, Philip P. Patient safety - a global priority. Bull World Health Organ. 2004 Dec;82(12):892.

4. National Patient Safety Agency (NPSA). Seven steps to patient safety in general practice [online]. 2009 [acesso 2013 Jun 30]. Disponível em: http:/ / www. nrls.npsa.nhs.uk/ resources / collections/sevensteps-to-patient-safety/

5. Agency for Healthcare Research And Quality. AHRQ Annual Report on Research and Management [online], 2004 [acesso 2012 Abr 12]. Disponível em: http://www.ahrq.gov/about/annrpt04/

6. Ministério da Saúde (BR). Portaria N. 529, de $1^{\circ}$ de abril de 2013: institui o Programa Nacional de Segurança do Paciente (PNSP). Brasília (DF): Diário Oficial da União; 2013 [acesso 2013 Jun 30]. Disponível em: http://bvsms.saude.gov.br/bvs/ saudelegis/gm/2013/prt0529_01_04_2013.html

7. Vincent, C. Segurança do paciente: orientações para evitar eventos adversos. São Caetano do Sul (SP): Yendis Editora, 2009.

8. Réa-neto A, Castro JEC, Knibel MF, Oliveira MC. Guia da UTI segura. São Paulo: Associação de Medicina Intensiva Brasileira; 2010.

9. Agency for Healthcare Research And Quality. Translation Guidelines for the AHRQ Surveys on Patient Safety Culture [online]. 2010 [acesso 2012 Abr 12]. Disponível em: http://www.ahrq.gov/ legacy/qual/patientsafetyculture/transguide.htm
10. Sorra JS, Nieva VF. Hospital survey on patient safety culture. AHRQ Publication n. 04-0041. Rockville, MD: Agency for Healthcare Research and Quality. Sep. 2004.

11. Sorra JS, Famolaro T, Dyer N, Nelson D, Smith SA. Hospital survey on patient safety culture 2012 user comparative database report. (Prepared by Westat, Rockville, MD, under Contract No. HHSA 290200710024C). Rockville, MD: Agency for Healthcare Research and Quality; February 2012.

12. Mello JF. Cultura de segurança do paciente em unidade de terapia intensiva: perspectiva da enfermagem [dissertação] Florianópolis (SC): Universidade Federal de Santa Catarina. Programa de Pós-Graduação em Enfermagem; 2011.

13. Gama ZAS, Oliveira ACS, Hernandez PJS. Cultura de seguridad del paciente y factores asociados en una red de hospitales públicos Españoles. Cad Saúde Pública. 2013 Fev; 29(2):283-93.

14. Hamdan M, Saleem AA. Assessment of patient safety culture in Palestinian public hospitals. Int J Qual Health Care. 2013 Apr; 25(2):167-75.

15. Nie Y, Mao X, Cui H, He S, Li J, Zhang M. Hospital survey on patient safety culture in China. BMC Health Serv Res. 2013 Jun 24;13:228.

16. Sammer CE, Lykens K, Singh KP, Mains DA, Lackan NA. What is patient safety culture? a review of the literature. J Nurs Scholarsh. 2010; 42(2):156-65.

17. Reason J. Human error: models and management. BMJ. 2000 Mar 18; 320(7237):768-70.

18. Claro CM, Krocockz DVC, Toffolleto MC, Padilha KG. Eventos adversos em Unidade de Terapia Intensiva: percepção dos enfermeiros sobre a cultura não punitiva. Rev Esc Enferm USP. 2011; 45(1):167-72.

19. Paese F, Sasso GTMD. Cultura da segurança do paciente na atenção primária à saúde. Texto Contexto Enferm [online]. 2013 Abr-Jun [acesso 2013 Set 12]; 22(2):302-10. [Disponível em: http:/ / www. scielo.br/pdf/tce/v22n2/v22n2a05

20. Tourgeman-Bashkin DSO, Zmora E. Causes of near misses in critical care of neonates and children. Acta Paediatr. 2008 Mar; 97(3):299-303.

21. Wagner C, Smits M, Sorra J, Huang CC. Assessing patient safety culture in hospitals across countries. Int J Qual Health Care. 2013 Jul; 25(3):213-21.

22. Lage MJ. Segurança do doente: da teoria à prática clínica. Rev Port Saúde Pública. 2010; 1 Temat(10):11-6.

23. Snijders C, Van Lingen RA, Molendijk A, Fetter WPF. Incidents and errors in neonatal intensive care: a review of the literature. Arch Dis Child Fetal Neonatal Ed. 2007 Sep;92(5):F391-8.

24. Sexton, BJ, Thomas, EJ, Helmreich, RL. Error, stress, and teamwork in medicine and aviation: cross sectional surveys. BMJ. 2000 Mar 18;320(7237):745-9. 
25. Wagner, LM, Capezuti, E, Rice, JC. Nurses' perceptions of safety culture in long-term care settings. J Nurs Scholarsh. 2009; 41(2):184-92.
26. Sujan, MA. A novel tool for organizational learning and its impact on safety culture in a hospital dispensary. Reliab Eng Syst Safe. 2012; 101: 21-34. 